\title{
Degradabilidade ruminal do feno de alguns alimentos volumosos para ruminantes
}

[Ruminal degradability of some roughage hays for ruminants feeding]

\author{
G.G.P. Carvalho ${ }^{1}$, A.J.V. Pires ${ }^{2}$, C.M. Veloso ${ }^{2,4}$, E. Detmann ${ }^{3,4}$, F.F. Silva ${ }^{2,4}$, R.R. Silva ${ }^{2}$ \\ ${ }^{1}$ Aluno de pós-graduação - UFV, Viçosa, MG \\ ${ }^{2}$ Universidade Estadual do Sudoeste da Bahia \\ Praça Primavera, 40 \\ 45700-000 - Itapetinga, BA \\ ${ }^{3}$ Departamento de Zootecnia - UFV - Viçosa, MG \\ ${ }^{4}$ Bolsista do $\mathrm{CNPq}$
}

\begin{abstract}
RESUMO
Avaliou-se a degradabilidade ruminal da matéria seca (MS), proteína bruta (PB), fibra em detergente neutro (FDN), da fibra em detergente ácido (FDA) e hemicelulose dos fenos de capim-elefante (Pennisetum purpureum), palma (Opuntia ficus), guandu (Cajanus cajan) e parte aérea da mandioca (Manihot esculenta) utilizando três bovinos mestiços machos, castrados, canulados no rúmen e mantidos em regime de pasto. Amostras de $4 \mathrm{~g}$ de cada alimento foram incubadas em duplicata no rúmen dos animais, nos períodos de 0, 6, 12, 24, 36, 48 e 72 horas. A degradabilidade potencial da PB dos fenos de capim-elefante e guandu foi semelhante, 83,9 e $81,2 \%$, respectivamente. Os maiores valores foram observados para os fenos de palma $(94,2 \%)$ e parte aérea da mandioca $(91,7 \%)$. A degradabilidade efetiva (DE) foi obtida considerando as taxas de passagem de 2, 5 e $8 \%$ hora. A maior DE observada para MS (60,5\%), PB (81,1\%), FDN (21,6\%), FDA $(27,9 \%)$ e HEM $(58,0 \%)$, na taxa de passagem de $5 \% / \mathrm{h}$, ocorreu com o feno de palma.
\end{abstract}

Palavras-chave: bovino, degradação in situ, forrageira, gramínea, leguminosa, alimento alternativo

\begin{abstract}
The ruminal degradability of dry matter (DM), crude protein (CP), neutral detergent fiber (NDF), acid detergent fiber (ADF) and hemicellulose (HEM) of elephantgrass (Pennisetum purpureum), forage cactus (Opuntia ficus), pigeon pea (Cajanus cajan) and cassava foliage (Manihot esculenta) hays was evaluated using three cannulated crossbred steers, kept on pasture. Samples of four grams of each hay were incubated in the rumen for 0, 6, 12, 24, 36, 48 and 72 hours. The CP potential degradability (PD) for elephantgrass and pigeon pea hays was similar, 83.9 and $81.2 \%$, respectively. Higher values were observed either for forage cactus $(94.2 \%)$ or cassava foliage (91.7\%) hays. The effective degradability (ED) was obtained considering the passage rates of 2, 5 and $8 \% / h o u r$. The forage cactus hay, at a passage rate of $5 \% / h$, showed the highest ED for DM (60.5\%), CP (81.1\%), NDF (21.6\%), ADF (27.9\%) and $\operatorname{HEM}(58.0 \%)$.
\end{abstract}

Keywords: cattle, in situ degradation, forage, grass, legume, alternative feed

Recebido em 27 de junho de 2005

Aceito em 24 de abril de 2006

E-mail: gleidsongiordano@yahoo.com.br

Apoio: UESB - Itapetinga, BA 


\section{INTRODUÇÃO}

A conservação de forragens é uma prática muito antiga devido ao fato de que a domesticação de herbívoros, em especial de ruminantes, deu-se em regiões de clima instável, com grandes períodos de frio intenso ou de secas prolongadas (Arcuri et al., 2003).

As informações acerca do efeito das espécies forrageiras sobre a característica de degradação são escassas, quando se considera capimelefante, palma, guandu e parte aérea da mandioca.

Rossi Júnior et al. (1997) destacaram a necessidade de uma avaliação mais precisa do valor nutritivo dos alimentos, concentrados e volumosos, devido à variação na composição química e à diversificação de métodos de análises das frações dos alimentos para a determinação de alguns parâmetros ruminais.

Forragens na forma de feno têm sido muito utilizadas e são de grande importância, particularmente em regiões onde a disponibilidade de água é reduzida ou a distribuição irregular das chuvas constitui fator limitante. Por isso, os problemas decorrentes da estacionalidade da produção no Brasil poderiam ser minimizados pelo armazenamento do alimento na forma de feno.

Segundo Ítavo et al. (2002), dos nutrientes necessários para suprir as exigências nutricionais para mantença, crescimento e ou produção de bovinos, a energia oriunda da degradação ruminal de celulose e de hemicelulose constitui a principal contribuição dos volumosos; porém, o nível de utilização da fração nitrogenada é importante na avaliação de alimentos e na especificação de exigências nutricionais dos ruminantes (Rossi Júnior et al., 1997).

De maneira geral, a estimativa da degradação ruminal dos alimentos tem sido considerada fundamental para se avaliar a quantidade de nutrientes disponível para os microrganismos do rúmen (Barbosa et al., 1998); além disso, permite avaliar a qualidade do nutriente, como, por exemplo, da proteína bruta que escapa da fermentação ruminal, fornecendo, conseqüentemente, aminoácidos disponíveis para digestão a partir do abomaso (Molina et al., 2002; Moreira et al., 2003).

Segundo Teixeira (1997), a técnica de sacos de náilon é considerada ideal para simular o ambiente ruminal dentro de determinado regime alimentar específico, apesar de o alimento não sofrer os efeitos de mastigação, da ruminação e do escape ruminal.

O objetivo do presente trabalho foi determinar a degradabilidade ruminal da matéria seca (MS), proteína bruta $(\mathrm{PB})$, fibra em detergente neutro (FDN), fibra em detergente ácido (FDA) e hemicelulose (HEM) dos fenos de capimelefante (Pennisetum purpureum), palma (Opuntia ficus), guandu (Cajanus cajan) e parte aérea da mandioca (Manihot esculenta).

\section{MATERIAL E MÉTODOS}

A incubação ruminal foi realizada em três bovinos machos, castrados, 3/4 holandês-zebu, canulados no rúmen, com peso vivo médio de $510 \mathrm{~kg}$, mantidos durante todo o período experimental em piquetes de capim-braquiária.

Antes da incubação ruminal, os fenos foram moídos em moinho com peneira de $5 \mathrm{~mm}$ e acondicionados em sacos de náilon com poros de $50 \mu \mathrm{m}$ de diâmetro e dimensões de $6 \times 10 \mathrm{~cm}$, na quantidade de aproximadamente $20 \mathrm{mg} / \mathrm{cm}^{2}$. Em cada animal foram incubados os fenos dos quatro alimentos, nos períodos de incubação de $0,6,12$, $24,36,48$ e 72 horas, sendo que cada amostra continha uma duplicata. Para o tempo correspondente a zero hora, os sacos foram lavados em água corrente, sem serem esfregados até a água sair limpa. A incubação foi realizada de forma a se retirar todos os sacos de náilon ao mesmo tempo, promovendo, dessa forma, lavagem uniforme do material. Após a retirada do rúmen, os sacos contendo o resíduo da forragem pós-incubação foram lavados em água corrente até que a mesma se apresentasse limpa, procedendo-se, então, à secagem em estufa a $65^{\circ} \mathrm{C}$ por 72 horas.

O procedimento para a determinação da degradabilidade de MS, PB, FDN, FDA e HEM foi obtido por diferença de peso encontrado para cada componente dos fenos, antes e após a incubação ruminal, e expresso em porcentagem. 
Os valores obtidos nas análises químicobromatológicas do capim-braquiária consumido pelos animais no período experimental (Tab. 1) e dos alimentos utilizados na incubação ruminal (Tab. 2) foram determinados segundo metodologias descritas por Silva e Queiroz (2002).

O delineamento experimental utilizado foi o de parcelas subdivididas, em que os três animais representaram os blocos; as quatro forragens, os tratamentos; e os sete tempos de incubação dos alimentos no rúmen, as subparcelas.
Tabela 1. Composição química (\%) do capimbraquiária (Brachiaria decumbens), consumido durante o período experimental

\begin{tabular}{lc}
\hline Item & $\begin{array}{c}\text { Composição } \\
\text { química }\end{array}$ \\
\hline Matéria seca total $^{1}$ & 26,52 \\
Proteína bruta $^{1}$ & 13,50 \\
Fibra em detergente neutro $^{1}$ & 67,80 \\
Fibra em detergente ácido $^{1}$ & 32,05 \\
Hemicelulose $^{1}$ & 35,75 \\
Proteína insolúvel em detergente ácido $^{1}$ & 2,90 \\
Extrato etéreo $^{1}$ & 4,51 \\
Cinzas $^{1}$ & 9,20 \\
\hline${ }^{1} \%$ da MS &
\end{tabular}

Tabela 2. Teores de matéria seca (MS), proteína bruta (PB), fibra em detergente neutro (FDN), fibra em detergente ácido (FDA), hemicelulose (HEM), proteína insolúvel em detergente ácido (PIDA), extrato etéreo (EE) e cinzas dos fenos usados na incubação ruminal

\begin{tabular}{lcrrr} 
Nutriente & Capim-elefante & Palma & Guandu & Parte aérea da mandioca \\
\hline MS (\%) & 90,60 & 89,64 & 90,67 & 91,20 \\
PB $^{1}$ & 7,88 & 6,30 & 11,82 & 19,59 \\
FDN $^{1}$ & 74,92 & 64,23 & 68,68 & 47,76 \\
FDA $^{1}$ & 41,92 & 21,09 & 46,64 & 28,11 \\
HEM $^{1}$ & 33,00 & 43,14 & 22,04 & 19,65 \\
PIDA $^{1}$ & 2,07 & 3,46 & 5,30 & 6,19 \\
EE $^{1}$ & 3,44 & 3,48 & 5,21 & 6,04 \\
Cinzas & 12,09 & 12,77 & 5,07 & 14,64 \\
\hline
\end{tabular}

As taxas de degradação da MS, PB, FDN, FDA e HEM foram calculadas, utilizando-se a equação proposta por Ørskov e McDonald (1979), e a degradabilidade da FDN da FDA e da HEM foi estimada utilizando o modelo de Mertens e Loften (1980).

Após os ajustes das equações para degradação da FDN, FDA e hemicelulose, procedeu-se à padronização de frações segundo a proposição de Waldo et al. (1972).

Os parâmetros não lineares, a, b e c, foram estimados por meio de procedimentos interativos de quadrados mínimos. As degradabilidades efetivas (DE) da $\mathrm{MS}$ e $\mathrm{PB}$, no rúmen foram calculadas utilizando o modelo $\mathrm{DE}=\mathrm{A}^{\prime}+\left(\mathrm{B}^{\prime} \mathrm{x}\right.$ $\mathrm{c} / \mathrm{c}+\mathrm{k})$, em que:

A' corresponde ao verdadeiro valor da fração imediatamente solúvel, obtida pela lavagem do material contido nos sacos no tempo zero, sem haver passado por tempo de incubação algum; B' é a fração potencialmente degradável por ação da microbiota $\left(\mathrm{A}+\mathrm{B}-\mathrm{C}^{\prime}\right)$, já que $\mathrm{A}+\mathrm{B}=\mathrm{A}^{\prime}+\mathrm{B}^{\prime}$, e $\mathrm{k}$ é a taxa estimada de passagem das partículas no rúmen.

Para a degradabilidade efetiva da FDN, FDA e HEM, utilizou-se o modelo $\mathrm{DE}=\mathrm{Bp}^{*} \mathrm{c} /(\mathrm{c}+\mathrm{k})$.

As DE da MS, PB, FDN, FDA e HEM foram estimadas para cada feno, levando-se em conta as taxas de passagem de 2,5 e $8 \% / h$, as quais podem ser atribuídas aos níveis de ingestão alimentar baixo, médio e alto, respectivamente, segundo preconizado pelo Nutrient... (1984).

\section{RESULTADOS E DISCUSSÃO}

Os parâmetros obtidos para as frações a, e b, e para a taxa de degradação $c$ da fração b podem ser observados na Tab. 3 . 
Tabela 3. Parâmetros da degradação ruminal da matéria seca (MS), proteína bruta (PB), fibra em detergente neutro (FDN), fibra em detergente ácido (FDA) e hemicelulose (HEM) dos fenos incubados no rúmen

\begin{tabular}{|c|c|c|c|c|c|}
\hline \multirow{2}{*}{ Feno } & & \multicolumn{3}{|c|}{ Parâmetros } & \multirow{2}{*}{$\mathrm{R}^{2}$} \\
\hline & & $\mathrm{a}$ & $\mathrm{b}$ & c & \\
\hline \multirow{5}{*}{ Capim-elefente } & MS & 7,85 & 50,63 & 4,27 & 99,23 \\
\hline & $\mathrm{PB}$ & 35,69 & 48,28 & 2,26 & 99,08 \\
\hline & FDN & 0,13 & 48,06 & 3,90 & 99,32 \\
\hline & FDA & 0,12 & 47,94 & 3,27 & 97,75 \\
\hline & HEM & 0,14 & 49,90 & 4,49 & 99,10 \\
\hline \multirow{5}{*}{ Palma } & MS & 14,09 & 66,47 & 10,34 & 98,56 \\
\hline & PB & 38,71 & 55,46 & 12,30 & 99,19 \\
\hline & FDN & 0,45 & 32,73 & 9,51 & 96,55 \\
\hline & FDA & 0,25 & 39,40 & 12,07 & 95,24 \\
\hline & HEM & 0,12 & 81,68 & 12,22 & 93,05 \\
\hline \multirow{5}{*}{ Guandu } & MS & 5,68 & 38,08 & 5,35 & 98,52 \\
\hline & $\mathrm{PB}$ & 28,13 & 53,09 & 2,41 & 98,81 \\
\hline & FDN & 0,09 & 33,88 & 3,15 & 98,56 \\
\hline & FDA & 0,01 & 36,21 & 3,52 & 95,53 \\
\hline & HEM & 0,34 & 30,00 & 1,76 & 95,22 \\
\hline \multirow{5}{*}{ Parte aérea da mandioca } & MS & 5,38 & 51,72 & 6,99 & 98,56 \\
\hline & $\mathrm{PB}$ & 17,53 & 74,18 & 6,53 & 99,15 \\
\hline & FDN & 0,15 & 38,40 & 5,26 & 98,03 \\
\hline & FDA & 0,07 & 32,33 & 4,93 & 97,84 \\
\hline & HEM & 0,15 & 57,84 & 5,94 & 97,98 \\
\hline
\end{tabular}
coeficiente de determinação.

As frações a, b e c da MS do feno da palma apresentaram maiores valores em relação aos outros alimentos testados. O feno de guandu e o feno de parte aérea da mandioca foram os alimentos que apresentaram as menores frações de a, 5,68 e 5,38, respectivamente. Para a fração $\mathrm{b}$, o feno de parte aérea da mandioca apresentou maior valor em relação ao guandu. A maior fração da PB ocorreu com o capim-elefante e com a palma. Para FDN, o maior valor foi encontrado no feno de palma. Valores semelhantes e intermediários foram observados para o feno de capim-elefante e parte aérea da mandioca, e o menor para o guandu.

Para a fração b da PB, o maior valor encontrado foi para o feno da parte aérea da mandioca. Nos demais alimentos, essa taxa foi menor, entretanto não houve grandes variações. Para a FDN, a maior fração foi obtida para o feno de capimelefante $(48,1 \%)$, seguido dos fenos da parte aérea da mandioca, de guandu e de palma com $38,4,33,9$ e $32,7 \%$, respectivamente. Para a FDA, o maior valor foi para o feno de capim- elefante $(48,0 \%)$ e o menor para o feno de parte aérea da mandioca $(32,3 \%)$.

Quanto à fração c, o maior valor obtido foi para a palma. A parte aérea da mandioca apresentou valor intermediário, e o guandu e o capimelefante valores semelhantes e inferiores. Portanto, as diferentes taxas de degradação encontradas nos alimentos analisados podem ter sido influenciadas pelos teores de MS, parede celular e conteúdo de carboidratos solúveis.

A palma destacou-se pela maior degradabilidade potencial (DP) da MS, e os fenos de capimelefante e da parte aérea da mandioca apresentaram valores semelhantes e intermediários, sendo o menor valor observado foi para o guandu. $\mathrm{Na} \mathrm{DP}$ da $\mathrm{PB}$, as degradabilidades dos fenos de capim-elefante e guandu foram semelhantes, 83,9 e $81,2 \%$, respectivamente. No entanto, os maiores valores foram observados para os fenos de palma $(94,2 \%)$ e da parte aérea da mandioca $(91,7 \%)$. A mesma tendência ocorreu para a DP da MS. O 
feno de capim-elefante destacou-se pela maior DP para FDN e FDA. Ao avaliarem a degradabilidade do feno de coast cross, Rodrigues et al. (2000) mencionaram valor de $70,5 \%$ para a DP da FDN. O valor obtido pelos autores foi superior a todos os alimentos testados no presente experimento.

O feno de palma apresentou mais de $80 \%$ de degradabilidade da HEM, seguido dos fenos da parte aérea da mandioca, capim-elefante e guandu (Tab. 4). Segundo Campos et al. (2003), a HEM é um polímero complexo formado por polissacarídes, sendo sua composição variável de acordo com a espécie forrageira. A digestibilidade da HEM está diretamente relacionada com a concentração de celulose e inversamente relacionada com a taxa de lignificação, uma vez que a HEM está mais associada a esse composto do que a qualquer outro polissacarídeo. Em ruminantes, a maior parte da celulose é digerida no rúmen, enquanto considerável porção da HEM escapa desse compartimento, sendo, então, fermentada nos intestinos (Van Soest, 1994).

Tabela 4. Degradabilidade potencial (DP) e degradações efetivas da matéria seca (MS), proteína bruta (PB), fibra em detergente neutro (FDN), fibra em detergente ácido (FDA) e hemicelulose (HEM) dos fenos calculadas para taxas de passagem de 2,5 e $8 \% / \mathrm{h}$

\begin{tabular}{|c|c|c|c|c|}
\hline \multirow{2}{*}{ Componente } & \multirow{2}{*}{ DP } & \multicolumn{3}{|c|}{ Taxa de passagem $(\% / \mathrm{h})$} \\
\hline & & 2 & 5 & 8 \\
\hline & \multicolumn{4}{|c|}{ Feno de capim-elefante } \\
\hline MS & 58,48 & 42,68 & 31,52 & 25,82 \\
\hline PB & 83,97 & 63,94 & 53,36 & 48,96 \\
\hline FDN & 48,12 & 31,81 & 21,09 & 15,77 \\
\hline FDA & 48,00 & 29,78 & 18,98 & 13,93 \\
\hline \multirow[t]{2}{*}{ HEM } & 49,97 & 34,57 & 23,64 & 17,96 \\
\hline & \multicolumn{4}{|c|}{ Feno de palma } \\
\hline MS & 80,56 & 71,44 & 60,54 & 53,22 \\
\hline PB & 94,17 & 89,39 & 81,12 & 75,29 \\
\hline FDN & 32,88 & 27,17 & 21,55 & 17,86 \\
\hline FDA & 39,50 & 33,89 & 27,93 & 23,76 \\
\hline \multirow[t]{2}{*}{ HEM } & 81,78 & 70,28 & 58,03 & 49,42 \\
\hline & \multicolumn{4}{|c|}{ Feno de guandu } \\
\hline MS & 43,76 & 34,74 & 26,70 & 22,28 \\
\hline PB & 81,22 & 60,08 & 48,34 & 43,36 \\
\hline FDN & 33,91 & 20,74 & 13,11 & 9,58 \\
\hline FDA & 36,21 & 23,09 & 14,96 & 11,06 \\
\hline \multirow[t]{2}{*}{ HEM } & 30,10 & 14,09 & 7,84 & 5,43 \\
\hline & \multicolumn{4}{|c|}{ Feno da parte aérea da mandioca } \\
\hline MS & 57,10 & 48,26 & 38,20 & 32,17 \\
\hline PB & 91,71 & 74,74 & 59,96 & 51,29 \\
\hline FDN & 38,46 & 27,86 & 19,72 & 15,26 \\
\hline FDA & 32,35 & 23,01 & 16,06 & 12,33 \\
\hline HEM & 57,93 & 43,34 & 31,45 & 24,68 \\
\hline
\end{tabular}

A DE foi obtida considerando taxas de passagem de 2,5 e $8 \% / \mathrm{h}$. A DE da MS, PB e HEM do feno de palma foi mais alta que a dos outros alimentos testados, o que o torna a fonte protéica de maior disponibilidade ruminal, pois a quantidade efetivamente digerida no rúmen influi diretamente na disponibilidade de nitrogênio para o crescimento dos microrganismos do rúmen e na quantidade de proteína que chega aos outros compartimentos do trato digestivo para digestão e absorção (Silva et al., 2002). Em relação aos outros fenos, o de guandu mostrou ser uma fonte protéica de baixa degradabilidade ruminal.

\section{CONCLUSÕES}

Entre os volumosos estudados, os fenos de palma e da parte aérea da mandioca apresentaram as 
melhores degradabilidades potenciais para a PB. $\mathrm{O}$ feno de palma foi a fonte protéica de maior degradabilidade efetiva ruminal. Quanto às frações fibrosas, FDN e FDA, o feno de guandu apresentou as piores taxas de degradação.

\section{REFERÊNCIAS BIBLIOGRÁFICAS}

ARCURI, P.B.; CARNEIRO, J.C.; LOPES, F.C.F. Microrganismos indesejáveis em forragens conservadas: efeito sobre $o$ metabolismo de ruminantes. In: VOLUMOSOS NA PRODUÇÃO DE RUMINANTES: VALOR ALIMENTÍCIO DE FORRAGENS, 2003, Jaboticabal. Anais... Jaboticabal/SP: FUNEP, 2003. p.51-69.

BARBOSA, G.S.S.C.; SAMPAIO, I.B.M.; GONÇALVES, L.C. et al. Fatores que afetam os valores de degradabilidade in situ da matéria seca de forrageiras tropicais: I. dieta basal. Arq. Bras. Med. Vet. Zootec., v.50, p.731-735, 1998.

CAMPOS, W.E.; SATURNINO, H.M.; SOUSA, B.M. et al. Degradabilidade in situ da silagem de quatro genótipos de sorgo com e sem tanino. II Fibra detergente neutro, fibra detergente ácido, hemicelulose e celulose. Arq. Bras. Med. Vet. Zootec., v.55, p.450-453, 2003.

ÍTAVO, L.C.V.; VALADARES FIHO, S.C.; SILVA, F.F. et al. Consumo, degradabilidade ruminal e digestibilidade aparente de fenos de gramíneas do gênero Cynodon e rações concentradas utilizando indicadores internos. Rev. Soc. Bras. Zootec., v.31, p.1024-1032, 2002.

MERTENS, D.R.; LOFTEN, J.R. The effect of starch on forage fiber digestion kinects in vitro. J. Dairy Sci., v.63, p.1437-1446, 1980.

MOLINA, L.R.; GONÇALVES, L.C.; RODRIGUEZ, N.M. et al. Digestibilidade in situ das frações fibrosas de silagens de seis genótipos de sorgo (Sorghum bicolor (L.) Moench) em diferentes estádios de maturação. Arq. Bras. Med. Vet. Zootec., v.54, p.169-179, 2002.
MOREIRA， J.F.C.; RODRIGUEZ， N.M.; FERNANDES, P.C.C. et al. Concentrados protéicos para bovinos. 1. Digestibilidade in situ da matéria seca e da proteína bruta. Arq. Bras. Med. Vet. Zootec., v.55, p.315-323, 2003.

NUTRIENT requirements of ruminant livestock. Farnhan Royal: CAB, 1984. 45p.

ØRSKOV, E. R.; McDONALD, I. The estimation of protein degradability in the rumen from incubation measurements weighted according to rate of passage. J. Agric. Sci., v.92, p.449-453, 1979.

RODRIGUES, P.H.M.; LUCCI, C.S.; MELOTTI, L. Efeitos da lasalocida sódica e proporção volumoso/concentrados sobre a degradabilidade in situ do farelo de soja e do feno coast cross (Cynodon dactylon 1. pers.) em vacas secas. Braz. J. Vet. Res. Anim. Sci., v.37, p.127-133, 2000.

ROSSI JÚNIOR, P.; BOSE, M.L.V.; BOIN, C. et al. Degradabilidade ruminal do amido de silagem de milho, farelo de soja e sorgo grão, em bovinos da raça nelore. Rev. Soc. Bras. Zootec., v.26, p.416-422, 1997.

SILVA, D.J.; QUEIROZ, A.C. Análise de alimentos: métodos químicos e biológicos. 3.ed. Viçosa: UFV, 2002. 235p.

SILVA, L.D.F.; RAMOS, B.M.O.; RIBEIRO, E.L.A. et al. Degradabilidade ruminal in situ da matéria seca e proteína bruta de duas variedades de grão de soja com diferentes teores de inibidor de tripsina, em bovinos. Rev. Soc. Bras. Zootec., v.31, p.1251-1257, 2002.

TEIXEIRA, J.C. Introdução aos métodos de determinação de digestibilidade em ruminantes. In: TEIXEIRA, J.C. (Ed.). Digestibilidade em ruminantes. Lavras: UFLA/FAEP, 1997. p.7-27.

VAN SOEST, P.J. Nutritional ecology of the ruminant. 2.ed. Ithaca: Cornell University, 1994. 476p.

WALDO, D.R.; SMITH, L.W.; COX, E.L. Model of cellulose disappearance from the rumen. J. Dairy Sci., v.55, p.125-129, 1972. 